\title{
A crise da Cristandade unitária e seus reflexos na Península Ibérica tardo-medieval
}

\author{
The crisis of the unitary Christianity and its effects \\ on late medieval Iberia \\ La Crisis de la Cristiandad unitaria y sus reflejos \\ en la Península Ibérica tardo-medieval
}

Fátima Regina Fernandes ${ }^{a}$

\begin{abstract}
Resumo: O presente trabalho analisa o Cisma do Ocidente (1378-1422) e seus efeitos no reino português. As opções de D. Fernando ao escolher ora Roma, ora Avignon ultrapassam as preocupações espirituais e ligam-se ao contexto político que se desenrola na Península Ibérica na segunda metade do século XIV. A crise dinástica castelhana leva a Guerra dos Cem Anos a este espaço da Cristandade e com ela os efeitos da fratura da Cristandade latina fomentada pelo antagonismo entre a França e a Inglaterra, opositores nesta guerra.
\end{abstract}

Palavras-chave: Cisma do Ocidente. Guerra dos Cem Anos. Península Ibérica Medieval.

Abstract: The present paper analyses the Great Schism (1378-1422) and its effects in the portuguese kingdom. The options of the king D. Fernando when choosing whether Rome, whether Avignon exceed spiritual worries and relate with the political context which develop on the Iberia Peninsula on the second half of the XIV century. The castilian dynastic crisis leads the Hundred Years' War to this space of the Christianity and with it the effects of the fracture of the Latin Christianity fomented by the antagonism between France and England, opponents in this war.

Keyword: Great Schism. Hundred Years’War. Medieval Iberia Peninsula.

Resumen: El presente trabajo analiza el Cisma del Occidente (1378-1422) y sus efectos en el reino de Portugal. Las opciones de D. Fernando al escoger o Roma, o Aviñón, traspasan las preocupaciones espirituales vinculándose al contexto político que se desarrolla en la Península Ibérica en la segunda mitad del siglo XIV. La crisis dinástica castellana lleva la Guerra de los Cien Años hacia este espacio de la Cristiandad y con ella los efectos de la fractura de la Cristiandad latina incrementada por el antagonismo existente entre la Francia y la Inglaterra, opositoras en esta guerra.

Palabras clave: Cisma del Occidente. Guerra de los Cien Años. Península Ibérica Medieval.

${ }^{a}$ Universidade Federal do Paraná. Professora associada IV do Departamento e Programa de História. Coordenadora do Núcleo de Estudos Mediterrânicos (NEMED) e pesquisadora PQ II do CNPq. 
A morte de Gregório XI em março de 1378 fez ressurgir na já abalada Sé Pontifícia de Roma o problema da sucessão. As propostas de Felipe IV, o Belo, para o controle pontifício e o exílio da Cúria Papal em Avignon tinham demonstrado o esgotamento das propostas de Teocracia pontifícia predominantes entre os séculos XI-XIII. O breve retorno de Gregório a Roma não tinha sido suficiente para resolver o problema. A sua morte deflagra uma dúplice e seqüencial eleição pontifícia promovida pelos Cardeais em inícios de 1378 que apoiaria as demandas políticas do reino de França comandado por Carlos V e da aliança lusoimperial que apoiava a eleição de um Papa romano. A Guerra dos Cem Anos atingia, mais uma vez, o âmbito eclesiástico, dividindo partidários dentro e fora da Igreja, cada um deles cioso de patrocinar uma fonte de legitimação de sua causa e de opróbrio do oponente. A Península Ibérica participaria de ambos os movimentos, dividida entre os partidários da facção franco-castelhana, pró-avinhonesa, e os que equilibravam a balança ora mantendo-se neutros, ora optando pela facção angloimperial, pró-romana, como seria o caso do reino português. O reinado de Fernando, iniciado em 1367, introduziria Portugal numa dinâmica pendular, buscando essencialmente autonomia frente ao reino vizinho de Castela. Observam-se, movimentos internos, ecos das tendências destes movimentos políticos que se desenvolviam além-Pirinéus, os quais serão objeto de análise neste trabalho.

A partir daqui analisaremos as correspondências que chegam ao reino português trazidas por emissários pontifícios, assim como os argumentos que sustentam os posicionamentos do rei em relação ao Cisma e suas conexões políticas. O discurso dos documentos e dos argumentos é de caráter universitário, um debate teológico enunciado e rebatido dentro de uma estrutura escolástica de disputatio que reflete a formação do alto clero nos reinos ibéricos na segunda metade do século XIV. De muitas formas, estes homens de saber participaram e contribuíram para os debates promovidos em toda a Cristandade latina, especialmente neste caso da duplicação ilegítima da Cúria Pontifícia, quando individualidades como o Cardeal Pero de Luna, o Bispo Pero Tenório, o Arcebispo de Braga Lourenço Vicente, o Bispo de Silves e Lisboa, Martinho e Mestre Gil do Sem esmeraram-se na defesa de suas posições com argumentos e muitas vezes com as armas e seu peso político dentro e fora destes reinos.

O problema original, o da dúplice eleição, seria debatido em termos da legitimidade da segunda eleição de Clemente VII, visto que em 08 de abril de 1378 treze dos dezesseis Cardeais, que haviam 
elegido e reconhecido por cerca de três meses Urbano VI como Papa, promoveriam nova eleição.

A 08 de maio chega a Portugal a notícia oficial da eleição de Urbano em Roma após conclave no qual esteve presente o Bispo de Lisboa à época, Agapito Colonna. O novo Papa, Bartolomeu Prignano, Arcebispo de Bari, no reino de Nápoles, sob o domínio da Casa de Anjou, desde o episódio das Visperas Sicilianas ${ }^{1}$, agradaria, certamente à aristocracia romana. A notícia chega ao conhecimento de D. Fernando na altura em que este recebia uma comitiva do Duque de Anjou na disposição de tratar uma aliança contra o reino de Aragão, senhor da Sicília. Tal notícia da eleição pontifícia seria divulgada por todos os Cardeais, inclusive o de Genebra, ao Sacro Império, Condado da Flandres e Ducado da Borgonha (Almeida, 1967, p. 375-376; Santos, 1988, p. 283).

Em agosto de 1378, chegaria outra carta ao reino português de alguns cardeais que teriam elegido novo Papa na cidade de Agnani, Condado de Fundi, o cardeal de Genebra, Clemente VII (Souza, 2013), parente de Carlos V, episódio que abriria um contexto de Cisma da Cristandade latina. Segundo Fernão Lopes, que colige documentação do século XV para narrar este episódio em sua Crónica de D. Fernando, à época da escolha de sucessor para Gregório XI havia forte pressão popular para que o novo Papa fosse romano ou pelo menos italiano. Tal condicionalismo levou ao consenso de que se poderia apresentar um candidato que satisfizesse a demanda popular, o Cardeal de Bari, o que pacificaria o povo e, em segredo, alçaria-se outro que efetivamente fosse elevado ao sólio pontifício. Proposta que teria desagradado apenas o Cardeal Pero de Luna ${ }^{2}$. Nesta segunda eleição, os Cardeais cismáticos teriam alegado que Urbano VI deveria ter renunciado após a sua elevação, pois ele seria o falso eleito que teria pacificado a ira popular, mas teria permanecido no poder de forma ilegítima. Seguir-se-ia, então, a partida do grupo de Roma e subsequente eleição de um segundo Papa em Fondi, reino de Nápoles, onde a rainha Joana dar-lhes-ia salvo-conduto para que passassem a Avignon, onde sob a guarda da Casa de Anjou, sua causa poderia prosperar.

\footnotetext{
${ }^{1}$ O episódio das Visperas Sicilianas corresponde a uma guerra iniciada por Pedro III de Aragão casado com Constança, neta de Frederico II Hohenstaüfen, herdeira do reino das Duas Sicílias que incluía Nápoles e Sicílias, em Palermo, na segunda-feira de Páscoa de 1282, contra os ocupantes deste reino, Carlos da Casa de Anjou. Este último conservaria apenas o reino de Nápoles e Pedro III a Sicília expandindo seus domínios ainda, pela maioria das ilhas mediterrânicas (Runciman, 1979, p. 211-223)

${ }^{2}$ Aragonês, catedrático da Universidade de Montepellier (Lopes, 1966, p. 300).
} 
Chegados a este refúgio, os Cardeais promoveriam a excomunhão de Urbano VI, cabendo as duas partes a condição e acusação mútua de cismáticos. Ocorre um fenômeno de desagregação intensa do grupo cardinalício original com esta saída de treze membros para Avignon, pois teriam permanecido três Cardeais itálicos junto ao Papa de Roma, os quais acabariam cooptados pelos ultramontanos. Pero de Luna dentre eles, pois não teria sido satisfeito em suas ambições e partiria para Avignon onde teriam-lhe acenado com a promessa de vir a assumir o trono pontifício, no entanto, inicialmente tornar-se-ia Núncio Geral de Avignon na Península Ibérica e só mais tarde veria suas ambições realizadas ${ }^{3}$. Diante desta lacuna, Urbano VI vê-se obrigado a criar novos Cardeais e nesta ocasião Agapito Colonna, bispo de Lisboa, seria feito Cardeal, criando um vazio institucional na diocese lisboeta, ocupado por D. Martinho, castelhano que é transferido da Sé de Silves, o qual apoiaria fortemente Clemente VII em Portugal. Enquanto que o Arcebispo de Braga, histórico concorrente do epigonismo compostelano na Península Ibérica, D. Lourenço Vicente, seria ferrenho defensor da causa urbanista, romana, no reino. Tratavase de um xadrez internacional que demandava um posicionamento dos bispos em posições estratégicas dentro dos reinos.

O problema central gerado por esta conjuntura é o de saber qual dos dois Papas teria a legitimidade de origem visto que haviam sido eleitos pelo mesmo grupo de Cardeais. O posicionamento a favor de cada um dos oponentes ultrapassaria o plano político; Urbano VI teria seu direito reconhecido por Catarina da Suécia e Catarina de Siena, enquanto que Clemente VII contava dentre seus apoiantes Vicente Ferrer, todos posteriormente canonizados e reconhecidos em seu tempo por sua santidade e sabedoria. A solução viria por duas vias: via cessionis, pela abdicação de um deles ou via concilii, pela deposição de ambos em Concílio, urgia, portanto, a defesa argumentada de sua própria legitimidade. As reflexões de vários pensadores anteriores a este contexto, mas já de oposição às prerrogativas pontifícias como Marsílio de Pádua, Guilherme de Ockham e mesmo João Quidort de Paris traziam o fermento da discórdia em suas concepções ao justificarem a deposição de um Papa incapaz ou a relativização da sua posição frente ao corpo dos fiéis. Tal debate, no seguimento do episódio de 1378, traria as posições do canonista Conrado de Gelnhausem, Epistola Concordiae e do teólogo Henrique de Langenstein, Epistola Pacis defendendo o

${ }^{3}$ Tornar-se-ía o Papa Bento XIII (1394-1409) deposto em Avignon (Almeida,1967, p. 377 e Santos, 1988, p. 335). 
direito de a Igreja depor um Papa considerado ilegítimo ou nefasto aos propósitos apostólicos, princípios reafirmados na Universidade de Paris. Além disso, o Cisma não constituía uma situação prevista ou regulada pela legislação canônica daí justificar-se a convocação de um Concílio sem a iniciativa papal, medida excepcional baseada na concepção de Igreja como congregatio fidelium. Esta discussão encaminharia para a proposta conciliarista que acabaria prevalecendo após o Concílio de Constança de 1417 que põe fim oficial ao Cisma, a partir do qual o Colégio cardinalício impor-se-ia como a hierarquia mais alta da Igreja, enfraquecendo o poder do Pontífice e sua autonomia decisória na cúpula da estrutura eclesiástica (Knowles e Obolenski, 1983, p. 447-449; Miehtke, 1993, p. 173-194).

Considerando-se as motivações políticas que levaram Portugal e Castela a adotarem um dos partidos devemos observar uma tendência dos reinos ibéricos em se manterem neutros em relação a esta divisão o maior tempo possível usando seu potencial apoio a Roma ou Avignon como instrumento de negociação frente aos blocos litigantes. Além disso, observamos também que, no caso português, oscilou-se entre as duas Sés Apostólicas num curto lapso de tempo, de janeiro de 1380 a agosto de 1381, devido à política pendular fernandina e sua pretensões na Península Ibérica. Castela, aliada desde a ascensão da dinastia Trastâmara à França, reluta, mas a adere a Avignon até maio de 1381; Aragão só em 1386 marcaria posição a favor de Clemente VII, tal como Navarra em 1390. Opções só bem compreendidas em conjunto, visto que o reino português e o castelhano duelam pela primazia política em seu espaço peninsular e lançam mão de aliados externos, Anjou, Inglaterra e Aragão para definir e avalizar suas escolhas determinando, assim, a opção do vizinho. Todos buscam o equilíbrio e a autonomia num contexto de instabilidade.

A geopolítica definia igualmente divisões internas dos reinos no que respeita aos posicionamentos frente ao Cisma. A Inglaterra apoiaria Roma, mas as pretensões autonomistas da Escócia a empurram ao apoio do Papa de Avignon. Na França, também não havia consenso quanto à defesa integral de alguma das duas Sés apostólicas visto que a Flandres e os feudos ingleses de Calais e Gasconha apóiam o Papa de Roma enquanto a Coroa francesa oficialmente patrocina Avignon. A mesma divisão ocorre no Sacro Império de Carlos IV e seus sucessores demonstrando que os posicionamentos eram sempre frágeis e diretamente ligados aos interesses políticos em jogo na Guerra dos Cem Anos que então servia de cenário a este Cisma. 
As Universidades também manifestariam posicionamentos diversos das autoridades laicas a que estavam submetidas; seria o caso da Universidade de Paris que manter-se-ía apoiante de Urbano VI e os Estudos Gerais de Lisboa que apoiariam Clemente VII mesmo antes do rei português. Tais posicionamentos deveriam-se aos interesses em jogo em cada um destes núcleos, mas os argumentos ganhariam forma acadêmica.

Passemos, então, aos debates que envolvem o esforço de mútuo convencimento das partes em relação ao Cisma do Ocidente. Para tanto, centraremos-nos nos reinos português e castelhano que refletem o conjunto do jogo de posições na Península e no além-Pirinéus ${ }^{4}$.

Fernão Lopes qualifica bem o Cisma na ótica política e teológica:

[...] cada huuns amdando a escolher, teverom com Urbano e Emperador, e os seus isso meesmo, e elRei de Imgraterra, e outros Reis e senhores; e com Clemente, elRei de Framça, e elRei de Castella, e elRei de Portugal, e elRei Daragom e desta guisa, por nossos peccados, foi estomçe o corpo místico da egreia feito com duas cabeças, assi como corpo momstruu, que era fea cousa de veer. (Lopes, 1966, p. 318-319)

A primeira notícia da eleição de Clemente VII chega a Castela e promove o destaque de ferrenho defensor da causa urbanista na pessoa do Arcebispo de Toledo, Pero Tenório e o campo de embate seria a Junta de Ilhescas realizada em 1378. O rei Henrique II consultaria aí seus prelados e teólogos sobre a legitimidade da eleição de Clemente VII e o argumento que predominaria era o de que se a eleição de Urbano fora pautada pelo medo da violência popular, a coroação no sólio pontifício ocorrera sem tumultos e com a presença de todos os Cardeais, o que conferia credibilidade à eleição ${ }^{5}$. Seguiria-se uma nova junta mais solene em Toledo com caráter de Assembleia de Cortes onde a presença do Núncio Pero de Luna e os esforços de Carlos V não seriam suficientes para abalar a opção de neutralidade do reino castelhano sobre esta questão. Um emissário urbanista foi enviado igualmente a Castela, Dom Mendo, Bispo de Córdoba, interceptado por um corsário catalão que o entrega a Pero de Luna e a Clemente VII sendo mantido em cativeiro por onze meses até sua fuga em 1379. Sabendo de tal estratagema, o Papa

\footnotetext{
${ }^{4}$ Sobre o Cisma vide Lopes, 1966, p. 293-305; Lopez de Ayala, 1997, p. 416-422 e Santos, 1988, p. 298-305, este último traz os textos compilados e os estudos de Raynaldi, famoso historiador da Igreja do século XVI.

${ }^{5} \mathrm{O}$ Cardeal de Santo Eustáquio escreveria ao Arcebispo toledano reforçando a aliança com Urbano VI enquanto Carlos V teria igualmente escrito a Henrique Trastâmara requisitando a seu aliado político o apoio a Clemente VII (Santos, 1988, p. 314-347).
} 
Urbano VI envia Frei Pedro, franciscano que aconselha o rei Henrique II, e convence-o a realizar nova Junta, a qual seria, no entanto, cancelada em função da inesperada morte do rei castelhano em maio de 1379, envenenado em San Domingos de la Calzada (Lopes, 1966, p. 307-309; Santos,1988, p. 316-317).

A morte do primeiro rei da dinastia recém-ascensa de Trastâmara produz muitos efeitos, dentre eles um posicionamento mais impositivo de D. Fernando, derrotado em duas guerras anteriores por este adversário, na última das quais sairia humilhado, inclusive em sua soberania, pelas condições do Tratado de Santarém. A isto se acrescente a quase simultânea morte de Carlos V em 1380, deixando herdeiro considerado incapaz e tutorado por seu tio, o Duque da Borgonha. Percebemos a visão de potencial vantagem do rei português numa conjuntura de fragilidade do eixo franco-castelhano.

D. Fernando tecia em 1378 alianças simultâneas com a Casa de Anjou, herdeira indireta da França e de Nápoles contra Aragão (Lopes, 1966, p. 263-264) e com a Inglaterra onde os exilados pró-castristas galegos agiriam como emissários portugueses desde 1373. Em relação à Castela, desde as Cortes de Leiria de 1376, ficara estabelecido o casamento da Infanta Beatriz de Portugal com D. Fradique, um irmão ilegítimo de D. Juan I, rei coroado em julho de 1379. Uma política de sobrevivência que a partir deste ano tomaria outro sentido. Daí que o posicionamento português em relação ao Cisma tenha se pautado pela neutralidade após a chegada da notícia de Fundi (Lopes, 1966, p. 317-319; Baptista, 1956, p. 76 e 128) e do esforço de D. Martinho em traduzir os cânones em vernáculo sobre a eleição pontifícia e conduzir a consulta aos letrados do reino (Almeida, 1967, p. 377; Santos, 1988, p. 289). Conselho ao qual não teria faltado o Arcebispo de Braga, D.Lourenço Vicente ${ }^{6}$,

\footnotetext{
${ }^{6}$ Desde 1371, a vacância do Arcebispado de Braga marcaria a oposição entre D. Lourenço e D. Martinho, visto que o cabido da Arquidiocese escolheria Martinho, bispo de Silves, como seu candidato. O então Papa Gregório XI não confirmaria a eleição e daria a Lourenço, cônego de Braga, a mitra bracarense. O novo Arcebispo Lourenço Vicente, impulsionado pelas ideias de Baldo, de quem fora discípulo em Bolonha, promoveria reformas internas que atingiriam interesses locais arraigados, pelo que, o cabido da Sé manifestar-se-ia duplamente insatisfeito. Gregório XI, pressionado pelo cabido, instauraria investigação para averiguar da veracidade das queixas. A condução da investigação caberia a Pero Tenorio, então bispo de Coimbra, mas já eleito Arcebispo de Toledo e a Vasco Domingues, cônego de Braga. Estes dois escolheriam um terceiro, Martinho, bispo de Silves, candidato do cabido de Braga que fora descartado anteriormente pelo Papa. O resultado foi a óbvia condenação de Lourenço pelos visitadores pelo que seria privado do Arcebispado. No entanto, tal sentença não teria efeito real, pois Lourenço não abandonaria a mitra e em 1378 recorreria a Roma, onde Urbano VI acabara de ser eleito. A 14 de fevereiro deste mesmo ano, Urbano VI absolveria Lourenço da condenação dos investigadores reintegrando-o na mitra bracarense, sentença que, no entanto, só seria executada em 1382 (Baptista, 1956, p. 85-89; Almeida, 1967, p. 358).
} 
assim como em nova reunião realizada em maio de 1379 que confirmaria a anterior decisão de neutralidade.

Em novembro de 1379, uma nova reunião proposta por D. Fernando para debater o tema, o Conselho de Salvaterra de Magos que contou com a presença do Arcebispo Pero Tenório, responsável, mesmo após a morte de Henrique II, por manter aliança com Portugal e a neutralidade dos dois reinos em relação ao Cisma. Decisão comunicada oficialmente ao rei de Castela manifestando-se uma política consonante entre os dois reinos em relação a esta questão. Apesar disso, neste mesmo mês, o Estudo Geral de Lisboa manifestaria-se a favor de Clemente VII discordando da decisão de Salvaterra ${ }^{7}$.

Numa aparente reviravolta inesperada, o rei português anuncia através da Declaração de Évora de janeiro de 1380 a adesão a Avignon, decisão que Fernão Lopes declara ter sido tomada contra opinião dos letrados e dos povos "seguindo mais a afeição da carne que o juízo da razão" (Lopes, 1966, p. 317-319). À primeira vista parece que o posicionamento da Universidade portuguesa teria efeito revisionista imediato em relação às decisões de Salvaterra, o que é um elemento a se ter em conta, mas adicionaremos outras hipóteses explicativas ${ }^{8}$. Após a morte de Henrique II, D. Fernando revê as bases de sua posição no eixo franco-luso-castelhano e tudo aponta para que o rei português projetasse um destaque em relação à Castela.

$\mathrm{O}$ reino francês e o Duque de Anjou felicitam imediatamente o rei português por sua decisão e este último destaca a eficácia de sua diplomacia em Portugal que teria acelerado a decisão do rei. Referiase às comitivas e certamente a D. Martinho, temporariamente Bispo de Lisboa que executaria sua função de emissário da causa angevinoavinhonesa levando os informes oficiais e granjeando os benefícios

\footnotetext{
${ }^{7}$ Juan I repassaria a informação de manutenção da neutralidade portuguesa ao rei de Aragão, refletindo a coordenação castelhana de uma política ibérica de autonomia em relação ao Cisma. Seria também de novembro de 1379 o posicionamento dos Estudos Gerais de Lisboa a favor de Clemente VII ( Baptista, 1956, p. 82-84 e 90).

${ }^{8}$ Os Estudos Gerais portugueses fundados em 1288/90 sofreram transferências constantes de Coimbra para Lisboa. Em 3 de junho de 1377, D. Fernando promove a última transferência medieval fixando-os em Lisboa (Sá, 1967, v. I, doct. 299, p. 5-8) e, numa carta de 07 de junho de 1380 Clemente VII, autoriza e reconhece esta fundação em Lisboa, além de recomendar a D. Martinho que revertesse os rendimentos de algumas Igrejas para a manutenção da Universidade (Idem, ibidem, v. II (1377-1408), docts. 351-2, p. 89-92) confirmando, portanto, a medida anteriormente estabelecida pelo rei português. Entendemos, portanto, que os defensores dos Estudos Gerais em Lisboa, viam em Clemente VII uma força legitimadora de suas pretensões frente à Coimbra, daí o precoce reconhecimento por aquele instituto, do Papa de Avignon. O fato é que Lisboa permaneceria como anfitriã da Universidade portuguesa por mais 160 anos, até pelo menos 1537 (ibidem, v. II, p. VII).
} 
de suas realizações ${ }^{9}$. Clemente VII agiria também diretamente sobre o Cabido da Sé de Braga fomentando a desobediência a D. Lourenço, adversário de sua causa no reino ${ }^{10}$. Portugal, com esta decisão, rompia com um consenso ibérico gerido por Castela e abria um canal direto de negociação com a França; partilhando de suas opções pontifícias, saía em vantagem frente a Castela que se mantinha neutra.

Esta hipótese fortalece-se com a análise da política matrimonial orquestrada por Fernando. Em maio de 1380, seus emissários chegam a Castela para alterar os acordos de 1376 propondo a substituição do consorte original pelo herdeiro do trono castelhano, filho de D. Juan I; com isto, D. Fernando ganhava tempo, pois o noivo em questão teria um ano de idade nesta ocasião ${ }^{11}$. Desta forma, sem abandonar a condição de aliado castelhano adiava a possibilidade de vinculação direta entre as duas Coroas; além disso, tais posicionamentos obrigariam a Inglaterra a concretizar sua aliança virtual com o reino português. Sintoma claro da eficácia desta política é a chegada em Portugal em meados de 1380 do Conde João Fernandes Andeiro, trazendo uma atualização das propostas de aliança do Duque de Lancaster e do casamento da Infanta portuguesa com seu filho ${ }^{12}$.

\footnotetext{
${ }_{9}$ Martinho, até então, permanecia bispo de Silves e o próprio Duque de Anjou prometeria recomendá-lo ao Papa de Avignon. De 7 de fevereiro de 1379, são os primeiros documentos relativos a Portugal, que se encontram nos registros de Avignon, um deles é uma bula na qual é pedido ao rei Fernando que aceitasse a indicação de Martinho para a diocese de Lisboa. Seria este bispo que levaria a Avignon, a declaração de obediência do reino português e novas cláusulas de negociação de Portugal com Anjou. Martinho levaria ainda, pessoalmente, em julho de 1380, à Corte dos Valois, a notícia da obediência portuguesa a Clemente VII. Além disso, tomaria posse da diocese de Lisboa em maio deste ano, instituição que Avignon, como vimos, solicitara desde o ano anterior mas que só agora o rei tinha condições de acatar oficialmente (Costa, 1970, p. 136-139 e 143-144). Na mesma época Fernando escreveria a Clemente VII pedindo que se criasse uma metrópole em Lisboa e que se erigissem outras dioceses no reino, todas sufragâneas de Lisboa. O bispo de Viseu e o abade de Alcobaça seriam encarregues pelo Papa de Avignon para elaborar as remodelações (Baptista, 1956, p. 85-87 e 100-106).

${ }^{10}$ Clemente VII transferiria, ainda que sem efeito, em meados de outubro de 1380, D. Lourenço Vicente para a diocese de Trani no sul da Itália e instigaria o cônego Vasco Domingues, incompatibilizado com Urbano VI devido à anulação de sua sentença contra Lourenço a resistir às suas pressões. A deposição e substituição de Lourenço seria novamente declarada pelo Papa de Avignon quando prenunciava-se a chegada dos aliados ingleses a Portugal, ficando no entanto, sem efeito (Baptista, 1956, p. 79, 86-89 e p. 102-114).

${ }^{11}$ Para tal fim mandaria comitiva a Castela a fim de desculpar-se pelo atraso no cumprimento das cláusulas que lhe foram impostas pelo Tratado de Santarém de 1373 (Arquivos Nacionais/ Torre do Tombo, Chancelaria de D. Fernando 1. II, f. 10 v). Para celebrar a união dos Infantes, os procuradores portugueses pediriam a alteração do estabelecido nas Cortes de Leiria de 1376 (Lopes, 1966, p. 313-315). Em agosto de 1380, este novo acordo seria selado nas Cortes de Torres Novas (Cortes Portuguesas. Reinado de D. Fernando I (1367-1383), v. 1, p. 167-169).

${ }^{12} \mathrm{O}$ Tratado de Estremoz de julho de 1380 que pressupunha a união de Beatriz com o filho do Conde de Cambridge (Lopes, 1966, p. 325-327 e Santos, 1988, p. 351).
} 
A pressão sobre Castela tornava-se insustentável e novo Conselho realizar-se-ia em Medina del Campo em novembro de 1380 sobre a questão do Cisma. Pero de Luna é confrontado com Francisco Huguccione numa assembleia onde vinte e três canonistas e muitos letrados testariam seus argumentos, mas o resultado ainda seria pela neutralidade castelhana (Lopez de Ayala, 1953, p. 70-75). Mas, em maio de 1381, Castela sairia de sua posição neutral e acompanharia Portugal na opção por Avignon na chamada Declaração de Salamanca proferida por Juan I. Urbano VI tendo conhecimento de tal decisão instruiria processo judicial eclesiástico contra o rei castelhano concluído em março de 1382 com sentença apostólica definitiva onde seria declarado hereje, cismático, blasfemo, réu de lesa majestade pontifical em primeiro grau, submetido a excomunhão maior, privação de seus reinos e senhorios, denegação de sepultura eclesiástica e mesmo convocação de Cruzada contra o Juan Enriquez que se dizia rei de Castela ${ }^{13}$.

Era de se esperar que a condição de D. Fernando fosse objeto das mesmas sanções, no entanto, estas não se apresentam. Existe, inclusive, um debate na historiografia se teria o rei português aderido de fato a Avignon. Fernão Lopes, escrevendo em meados do século XV, declara que tal opção teria sido feita por Portugal (Lopes, 1966, p. 317-319). Já Frei Manoel dos Santos, cisterciense que escreve no século XVIII defende que o rei não teria aderido a Clemente VII, mas sim o Bispo de Lisboa, D. Martinho e que D. Fernando apenas teria tolerado esta opção episcopal devido à remissão de ânimo e brandura natural que lhe era própria ${ }^{14}$. Fortunato de Almeida escrevendo na década de ' 30 do século XX declara ter encontrado atos pontifícios de Clemente VII relativos ao reino português entre abril de 1380 e junho de 1381, o que apontaria para a existência desta opção régia avinhonesa (Almeida, 1967, p. 378). Tal dúvida deve-se à incerteza cronológica de outro Conselho: o de Santarém realizado em 1381 ou 1383 no qual o clero português teria recusado apoiar Avignon.

Todo o jogo tecido por D. Fernando aproximando-se de Anjou/ Avignon em janeiro de 1380 daria seus frutos: declararia-se nova guerra

\footnotetext{
${ }^{13}$ Santos, 1988, p. 321-332. Estas condenações espirituais envolveriam a perda do trono, condição perigosa para qualquer reino neste contexto, especialmente para Juan I de Castela, que lidava com várias forças sócio-políticas internas concorrentes à monarquia, especialmente desde a ascensão de seu pai ao trono. Além disso, o Duque de Lancaster por ser casado com a filha de Pedro, o Cruel, manifestaria ainda por muito tempo pretensões expressas ao trono castelhano, o que transformava estas penas espirituais em sérias ameaças à integridade da dinastia Trastâmara.

${ }^{14}$ Frei Manoel dos Santos chama em defesa de sua opinião o analista Raynaldi em sua História Eclesiástica (Santos, 1988, p. 333-334).
} 
contra Castela por força da vontade do rei português contra seu Conselho (Lopes, 1966, p. 322-323) a fim de vingar humilhações anteriores ${ }^{15} \mathrm{e}$ em julho de 1381 os mais que nunca aliados ingleses desembarcariam a mando de Ricardo II em Lisboa com tropas de apoio a Portugal ${ }^{16}$. O rei português vivia um momento único em que de peão passava a rei no encaminhamento da política peninsular frente ao eixo franco-castelhano. Mas isto tinha um preço: já ao desembarcarem, os ingleses recusam-se a ouvir missa do clero português por eles designado cismático. O Conde de Cambridge cobraria de Fernando o reconhecimento de Urbano VI como pontífice legítimo em troca de seu apoio político e bélico. Assim, a 19 de Agosto de 1381 na Catedral de Lisboa, o rei português declararia a sua obediência oficial a Urbano $\mathrm{VI}^{17}$, posição oficializada no chamado Conselho de Santarém que anteporia o Arcebispo de Braga, Lourenço Vicente, liderando o episcopado pró-urbanista e Pero de Luna na defesa de Avignon.

Voltamos aqui à questão da inexistência de uma opção anterior a Avignon por parte da monarquia portuguesa. Fernão Lopes reconhece a realização desta reunião que deveria fazer o reino retornar ao Papa de Roma datada de 19 de agosto de 1381 (Lopes, 1966, p. 363). Manoel dos Santos, por sua vez, argumenta que Pero de Luna, após conseguir a adesão de Juan I de Castela a sua causa em maio de 1381, passaria ao reino português tentando em vão cooptar Fernando para Avignon, pelo que ficaria confirmada a constante permanência do reino com Roma; recorrendo a Raynaldi, confirma a datação atribuída por Fernão Lopes (Santos, 1988, p. 336). Fortunato de Almeida reconhece igualmente a data de 1381 para realização da Assembleia, mas não duvida da anterior opção de Fernando por Clemente VII e interpreta tal reunião como um retorno ao apoio à Cúria de Roma. Outro autor bastante avalizado no tema, Júlio César Baptista, escrevendo na década de '50 do século XX, faz ampla reflexão tentando mostrar o equívoco desta datação a partir das deslocações de Pero de Luna em função do calendário litúrgico, das contingências políticas e da composição do conselho português atribuindo a data de 23 de fevereiro de 1383, à realização deste Conselho

\footnotetext{
${ }^{15}$ No entanto, a guerra começaria com o desastre naval de Saltes em julho de 1381 quando cairiam cativos dos castelhanos cerca de seis mil portugueses levados a Sevilha onde ficariam até setembro de 1382 após a assinatura do Tratado de Elvas-Badajoz de agosto 1382 (Lopes, 1966, p. 351-354 e 431-435 e Santos, 1988, p. 356-358).

${ }^{16} \mathrm{O}$ Duque de Lancaster e o Conde de Cambridge (Arquivos Nacionais/Torre do Tombo, Chancelaria de D. Fernando, 1. III, f. 7v ; Lopes, 1966, p. 357-359 e 367 e Santos, 1988, p. 359).

${ }^{17}$ No mesmo dia realizaria-se o casamento da Infanta Beatriz e Edward (Lopes, 1966, p. 363-364 e Russell, 1940, p. 29).
} 
de Santarém $^{18}$. Segundo Baptista, só depois da saída das tropas inglesas de Portugal, Pero de Luna atreveria-se a ir a este reino, fato que só ocorre após as pazes seladas entre Portugal e Castela em agosto de 1382 (Baptista, 1956, p. 143-4). Baptista, por sua vez, não questiona a anterior adesão portuguesa a Avignon, posição que partilhamos em função da argumentação anteriormente feita pelos autores a partir de documentação chancelar, eclesiástica ${ }^{19}$ e cronística. António Domingues de Sousa Costa, por sua vez, reconhece a data de agosto de 1381 como a de retorno português ao apoio de Roma, pautado em documentação eclesiástica e civil bastante avalizada (Costa, 1982, p. 293).

Portugal permaneceria, portanto, a favor de Roma desde pelo menos agosto de 1381 e Castela a favor de Avignon até ao fim do Cisma em 1417. Interessa-nos, assim, determo-nos nos argumentos trazidos pelas partes, visto que se retorna à questão original da legitimidade das eleições de 1378 e tal debate apresenta boa síntese da questão com um distanciamento de três a cinco anos, apresentando ainda um posicionamento português que não mais se alteraria até o fim da divisão pontifícia.

A composição da Assembleia é pouco conhecida, sabe-se da presença de Pero de Luna e do Bispo da Guarda seu apoiante que nada alega e nota-se a ausência do forte apoiante clementino em Portugal, D. Martinho privado da diocese olisipina em decorrência das pressões de Urbano $\mathrm{VI}^{20}$. Quanto ao episcopado português pró-urbanista alega-se a presença do Arcebispo de Braga, discípulo de Baldo em Bolonha, dos bispos do Porto e Lamego (Santos, 1988, p. 336-340; Almeida, 1967, p. 379-380).

Pero de Luna abriria a seção trazendo a questão central, o casu, os cardeais que indicaram a deposição de Urbano VI têm a verdade ou deturpam os fatos? O zelo cardinalício poderia ser equivocado? Clemente VII tem a verdadeira investidura?

Apresenta sua argumentação em favor do crédito da verdade que se deve dar aos Cardeais em razão de sua autoridade, da veracidade do seu conhecimento e da necessidade do Direito. A sua autoridade viria em virtude de seu estado, comparados aos levitas do Antigo Testamento,

\footnotetext{
${ }^{18}$ Toda esta discussão em boa parte deve-se ao fato do texto do documento na Biblioteca Vaticana apresenta-se sem datação.

${ }^{19}$ Por exemplo, a supracitada carta de 7 de fevereiro de 1379 do Papa Clemente VII ao rei Fernando em favor de D. Martinho.

${ }^{20}$ D. Martinho seria substituído em agosto de 1381 por Juan Gutierrez ex-apoiante dos Castro e exilado em Inglaterra que chegaria a Portugal na comitiva do Duque de Lancaster (Baptista, 1956, p. 133). Vide ainda propósito destes argumentos Costa, 1982, p. 356-420.
} 
no Cristianismo os Cardeais deviam ser testemunhas reconhecidas em questões dubitativas como esta de quem é o verdadeiro Papa. Em virtude de seu ofício teriam igualmente autoridade, pois lhes cabia a função de eleger Papa. Devem ser reconhecidos ainda em virtude de sua dignidade original e historicamente incontestável (Baptista, 1956, p. 146-147).

A História e o Direito vigente seriam razão comprobatória da veracidade do conhecimento dos Cardeais. Neste caso específico, só eles têm perfeito conhecimento dos fatos que envolveram a eleição de Urbano VI desde os tumultos populares até as deliberações internas do Conclave.

Os poderes temporais devem dar crédito aos testemunhos dos Cardeais para fazer valer a eleição realizada e fazer cumprir o Direito. A certeza da fé é a única que pode manter a unidade da Igreja, daí a necessidade de reconhecer o Papa que os Cardeais reconhecem e refutar aquele que eles repudiam.

Baptista resume bem a explanação do Arcebispo aragonês:

Portanto, à luz do direito, da razão e da história, o mundo cristão é obrigado, sob pena de quebrar a unidade da Igreja, a obedecer ao Papa que pelos Cardeais for declarado legítimo. Este é indubitavelmente Clemente VII. (Baptista, 1956, p. 148)

Até aqui percebemos uma tendência de alegação centrada na ideia de unidade da Igreja enquanto representante do Corpo místico de Cristo no mundo temporal. Os Cardeais, nesta proposta, seriam a cúpula da Igreja e qualquer questionamento às suas decisões seria potencial ocasião de divisão e incerteza da fé. Encaminhava-se para uma tendência de sobreposição do Colégio cardinalício à proeminência dos Pontífices, uma transição que começara nos episódios de Bonifácio VIII e Felipe, o Belo em Agnani e terminaria no movimento Conciliarista e na crescente regionalização do clero. Nesta argumentação de Pero de Luna, vemos que os apoiantes de Clemente VII aceleram este processo fundamentando suas posições na autonomia dos Cardeais, mas buscam reconstruir a unidade, mesmo que à volta de Avignon, pois a divisão não interessa a ninguém, até os reinos padecem ao conviver com uma legitimidade pontifícia parcial, fragmentada e questionável.

A resposta do episcopado português contestaria a credibilidade dos Cardeais no episódio da eleição de Clemente VII enquanto o reforço da argumentação avinhonesa assentava-se na legitimidade da deposição de Urbano VI. Os portugueses centraram-se na ilegitimidade da eleição de Clemente VII. 
Questiona-se a credibilidade do testemunho dos Cardeais e a ausência da consideração de que outros podem conhecer melhor a verdade do que eles. Como testemunhas do caso em questão não devem ter credibilidade, pois são testemunhas opositoras públicas de Urbano VI e, portanto, comprometidas, pois são parte interessada no litígio. $\mathrm{O}$ proveito ou a perda desta causa interessa-lhes diretamente, portanto, seus testemunhos não têm fé.

Além disso, alega-se a contradição flagrante de um mesmo grupo de Cardeais promoverem a eleição seqüencial de dois Papas, conservando, portanto, para si, depois da primeira eleição e investidura, o direito de eleger outro Papa, como ocorrera no caso de Clemente VII. Este direito só caberia aos Cardeais quando não houvesse um ocupante vivo no sólio Pontifício, depois de ocupado cessaria o direito atribuído ao Colégio cardinalício; em outros termos, eleito um Papa, os Cardeais não têm mais poder algum sobre ele (Santos, 1988, p. 336-40; Baptista, 1956, p. 150-1). Neste ponto, chegamos à defesa de uma posição questionadora das tendências da proposta avinhonesa, percebendo que os defensores da primazia urbanista romana relativizavam a potencial sobreposição dos Cardeais aos Pontífices, reforçando-se, neste caso, a maior autonomia dos Papas em relação aos Cardeais.

O Deão de Coimbra, Rui Lourenço destacaria ainda a contradição na atuação e no testemunho dos Cardeais. Estes tinham anunciado e reconhecido Urbano VI como legítimo, recebem dele os sacramentos e pouco tempo depois o declaram ilegítimo. Se a primeira afirmação era falsa, os Cardeais perdem o crédito, pois reconheceram a Urbano as honras pontifícias, o que se repercute por toda Cristandade, sabendo que ele não era legítimo. E se o primeiro reconhecimento de legitimidade de Urbano era verdadeiro, então, o reconhecimento de Clemente seria falso (Baptista, 1956, p. 151).

Um Doutor da Catedral de Viseu, por sua vez, exploraria o argumento da falta de liberdade na eleição de Urbano VI devido ao medo imposto pelas massas populares. Ele contra-argumenta que à luz do Direito o medo e a violência não tiram a voluntariedade da escolha e neste caso, mesmo que a escolha tivesse sido feita sob pressão, os Cardeais deveriam conservar a eleição original (Baptista, 1956, p. 151).

O Mestre Gil do Sem apresentaria sua argumentação destacando a duplicidade dos Cardeais que durante três meses reconheceram a dignidade legítima de Urbano VI sem referências a uma potencial 
violência geradora de sua eleição ${ }^{21}$. Frei Lobo completaria a exposição centrando-se na defesa de que no caso de Urbano VI ser ilegítimo, toda a Igreja teria errado durante o interstício das duas eleições, o que foi por ele, à luz do Direito considerado um absurdo. Frei Vicente apresenta ainda acusação de que diante de dois reconhecimentos consecutivos de Papas diferentes deveria-se considerar cismáticos os seguidores do segundo eleito (Baptista, 1956, p. 152-153).

Em síntese, o resultado do Conselho de Santarém marcaria a permanência da adesão portuguesa ao Papa Urbano VI de Roma. Extraise ainda dos argumentos que prevalecem o reconhecimento ao corpo cardinalício do direito de realizar a eleição pontifícia; autoridade sobre os Papas que cessava ao fim do pleito. Ao anunciarem à Cristandade o reconhecimento canônico ao Papa Urbano VI, tal decisão não poderia ter sido revista pelos mesmos Cardeais que o elegeram e apoiado nestes argumentos o clero português reconhecia legitimidade apenas a este Pontífice.

No seguimento, D. Lourenço Vicente seria oficialmente reconhecido Arcebispo de Braga por um Concílio diocesano bracarense realizado em novembro de 1381 por força das pressões vindas de $R_{0 m a}^{22}$, o que teoricamente resolveria a divisão interna entre o cabido e o bispo. D. Martinho, substituído por Juan Gutierrez desde agosto de 1381 . Reapareceria, no entanto, no cenário político, na medida em que o reino português tenderia a novas inflexões pró-avinhonesas. As pazes lusocastelhanas de 1382 frustrariam os aliados ingleses que se retiram do reino português e ainda que os acordos com Portugal permaneçam no horizonte diplomático, na prática, o acordo de Salvaterra de Magos de março de $1383^{23}$. Tratado que ligaria a descendência do reino à Coroa castelhana fruto da progressiva incapacidade do rei D. Fernando e do controle de ações em mãos da rainha Leonor Teles, reaproximaria o reino dos cismáticos castelhanos. Pero de Luna seria o artífice da aliança matrimonial que resultara neste tratado e o procurador que assinaria do lado castelhano seria o Arcebispo de Santiago, João Garcia

${ }^{21}$ Neste tema, Fernão Lopes em sua Crônica de D. Fernando retoma a discussão do medo como móbil de uma falsa eleição e destaca os argumentos de João de Liniano e Bartolomeu de Saliceto à época do debate, quais sejam que dando-se o caso de ter sido assim, por que os Cardeais não escreveram ao Imperador e aos reis cristãos alertando sobre esta pressão? Por que aceitaram os benefícios de Urbano VI? Por que lhe enviaram petições onde o reconheciam como Papa? (Lopes, 1966, p. 303-305).

${ }^{22}$ Neste Concílio seria oficializada a sentença favorável de fevereiro de 1379 (Almeida, 1967, p. 466).

${ }^{23}$ Assinam este tratado em nome do rei D. Fernando, os bispos Martinho de Silves e os bispos da Guarda e de Coimbra, todos pró-Avignon. 
Manrique (Lopes, 1966, p. 265-6; Lopez de Ayala, 1953, p. 78; Costa, 1970, p. 380-381), notando-se a ausência de Pero Tenorio. Seria ainda, o Núncio avinhonês quem, em maio de 1383, celebraria o enlace matrimonial em Badajoz e declaria a Infanta Beatriz apta para consumar o matrimônio apesar dela não ter completado ainda os doze anos canonicamente exigidos ${ }^{24}$. Avignon e a França agem, mais uma vez, através de Castela para atrair Portugal para seu núcleo. Urbano VI o perceberia e de março a abril de 1383 , intensificaria a emissão de bulas condenatórias a Castela, contra a qual convocaria novamente Cruzada ${ }^{25}$.

A morte de D. Fernando e os sucessos ligados ao movimento de $1383-85^{26}$ definiriam a opção portuguesa por Roma, partidarismo que inclusive fortaleceria a tese de ilegitimidade de Juan I e de sua descendência para suceder o rei português nas Cortes de Coimbra de $1385^{27}$.O Doutor João das Regras, discípulo de Baldo, apresentaria nesta Assembleia belíssima peça de argumentação jurídica na qual sob muitos argumentos diferenciados, mas assentes no Direito Comum e Canônico defenderia a escolha de D. João, Mestre de Avis, como o mais legítimo dentre os candidatos que se apresentavam à sucessão do trono português. Assim, adicionalmente ao confronto bélico que se arrastaria ainda por muitos anos, a argumentação em bases jurídicas apresentavase indispensável à definição e legitimidade do futuro rei, apto ou não a assumir suas funções, no caso de D. João I, fundador da dinastia avisina, reconhecido como cristão, combatente de seus opositores políticos, mas também dos cismáticos castelhanos, apresentados pelo Doutor em Leis e Degredos pela Universidade de Bolonha como agentes nefastos à unidade da Cristandade latina.

${ }^{24}$ E seria o mesmo D. Martinho quem acompanharia a Infanta portuguesa Beatriz a Castela onde seria recebida por seu marido Juan I Trastâmara. (Costa, 1970, p. 385-387 e Lopes, 1966, p. $455-456$ e $459-461)$.

25 De 31 de março de 1383, a bula Deum Laudabilium, onde Urbano "nomeava o Duque de Lencastre comandante chefe dos exércitos católicos contra o Tratâmara, deposto por sentença pontifícia". Uma outra bula do mesmo dia, Deum censemus concede graças espirituais a quem combater Juan I. A 8 de abril de 1383, a bula Dudum contra iniquatis proclamava oficialmente a Cruzada e outra bula da mesma data, Cum in vinea Domin, $i$ anunciaria em Castela as penas dos que apoiassem Clemente VII (Baptista, 1956, p. 141-142).

${ }^{26}$ Movimentações de dezembro de 1383 que acarretariam a morte violenta do Bispo Martinho, reencaminhado à Sé lisboeta de cuja torre seria lançado, identificado pela turba como agente castelhano em Portugal . Ironicamente seria eleito em Avignon neste mesmo mês Cardeal em retribuição a seus bons serviços a Clemente VII no reino português, benefício que naturalmente não poderia mais usufruir (Lopes, 1991, p. 27-30 e Baptista, 1956, p. 109-110 e p. 172).

${ }^{27}$ Cortes às quais estaria presente o Arcebispo Lourenço Vicente, premente defensor inclusive pelas armas, da causa de Avis e de Roma até sua morte em 1397 (Lopes, 1991, p. 392). 
Pois sse o Papa Urbano nosso pastor e Deos sobre a terra, nos manda e amoesta que perssigamos todollos çismaticos emfiees assi como hereges e membros talhados da egreja, avemdoos por escomungados da mayor escomunhom [...] como tomariamos nos por nosso rei e senhor, quem foy e he tam claramente cõtra elle e cabeça da tamta malldade e çisma? Certamente nom he de dizer [...] Pois avermos nos, de tomar çismatico imfiell herege por nosso rei e senhor, que o dereito e nosso senhor o Papa deffemde! - Nom queira Deos que tall erro passe per nos. (Lopes, 1991, p. 401)

Uma defesa de posição do reino português que no contexto maior da Guerra dos Cem Anos tem correspondências e ecos de ressonância, colocando Portugal numa condição de agente ativo no jogo político internacional destes séculos XIV e XV. A pena dos letrados fortaleceria a espada dos partidários de Avis e de Urbano VI dentro e especialmente fora do reino, reconhecido na Península Ibérica como partidário e aliado de Inglaterra e do Sacro Império Romano Germânico e, portanto, fora da órbita do eixo franco-castelhano. A definição portuguesa pressionaria o posicionamento declarado dos outros reinos ibéricos que optariam por Avignon, situação de aparente isolamento de D. João I compensado por uma projeção e apoio que alcançaria um âmbito além-peninsular.

\section{Referências}

ALMEIDA, Fortunato de. História da Igreja em Portugal. Porto: [Ed. Damião Peres] Portucalense Editora, 1967. v. I. 531p.

Arquivos Nacionais/Torre do Tombo. Chancelaria de D. Fernando. 4 livros (manuscrito). BAPTISTA, J. César. Portugal e o cisma do Ocidente. Lusitania Sacra, Lisboa, n. 1, p. 64-179, 1956.

SÁ, A. Moreira de. Chartularium Universitatis Portugalensis. Lisboa: Instituto de Alta Cultura, Centro de Estudos de Psicologia e de História da Filosofia, Universidade de Lisboa, 1967. v. I, (1288-1377). 672p.

Cortes Portuguesas. Reinado de D. Fernando I (1367-1383). Lisboa: Centro de Estudos Históricos da Universidade Nova de Lisboa-INIC/JNICT, 1990. 200p.

COSTA, António Domingues de Sousa. Monumenta Portugaliae Vaticana. Braga-Porto: Editorial Franciscana, 1970. v. II. 604p.

COSTA, António Domingues de Sousa. Monumenta Portugaliae Vaticana. Braga-Porto: Editorial Franciscana, 1982. v. III-1. 874p.

FRIGHETTO, Renan; GUIMARÃES, Marcella Lopes (Org.). Instituições, poderes e jurisdições. Curitiba: Juruá/CNPq/NEMED, 2007. p. 137-155.

KNOWLES; OBOLENSKY. Nova História da Igreja. Idade Média. Petrópolis: Vozes, 1983. v. 2. 405p. 
LOPES, Fernão. Crónica de D. Fernando. Porto: Civilização, 1966. 527p.

LOPES, Fernão. Crónica de D. João I. Barcelos-Porto: Civilização, 1991. 455p.

LOPEZ DE AYALA, Crónica del Rey Don Juan. In: Crónicas de los Reyes de Castilla. Madrid: Biblioteca de Autores Españoles, 1953.

LOPEZ DE AYALA, Pero. Crónica del Rey Don Pedro y del Rey Don Enrique. Buenos Aires: SECRIT, 1997. v. II. 574p.

MIEHTKE, Jürgen. Las ideas políticas de la Edad Media. Buenos Aires: Biblos, 1993. $218 \mathrm{p}$.

RUNCIMAN, Steven. Visperas Sicilianas: Uma historia del mundo mediterráneo a finales del siglo XIII. Madrid: Alianza Editorial, 1979. 335p.

RUSSELL, P. E. João Fernandes Andeiro at the Court of John of Lancaster: 1371-1381. Revista da Universidade de Coimbra, Coimbra: Faculdade de Letras da Universidade de Coimbra, n. XIV, p. 20-30. 1940.

SANTOS, Fr. Manoel dos. Monarquia Lusitana. 3. ed. Lisboa: Imprensa Nacional-Casa da Moeda, 1988. Parte VIII. 800p.

SOUZA, José Antonio de C. R.; BAYONA AZNAR, B. (Org.). Doctrinas y relaciones de poder en el Cisma del Occidente y en la época conciliar (1378-1449). Zaragoza: Prensas de la Universidad de Zaragoza, 2013. 386p.

SOUZA, José Antonio de C. R. de (Org.). As relações de poder: do Cisma do Ocidente a Nicolau de Cusa. Porto Alegre: Edições EST, 2011. 235p. 